\title{
Identification of goat milk powder by manufacturer using multiple chemical parameters
}

\author{
Rebecca J. McLeod, ${ }^{* 1}$ Colin G. Prosser, $†$ and Joshua W. Wakefield* \\ *Oritain Global Ltd., Private Bag 50034, Mosgiel, Otago 9053 New Zealand \\ †Dairy Goat Co-operative, 18 Gallagher Drive, Hamilton, 3206 New Zealand
}

\begin{abstract}
Concentrations of multiple elements and ratios of stable isotopes of carbon and nitrogen were measured and combined to create a chemical fingerprint of production batches of goat whole milk powder (WMP) produced by different manufacturers. Our objectives were to determine whether or not differences exist in the chemical fingerprint among samples of goat WMP produced at different sites, and assess temporal changes in the chemical fingerprint in product manufactured at one site. In total, 58 samples of goat WMP were analyzed by inductively coupled plasma-mass spectrometry as well as isotope ratio mass spectrometry and a suite of 13 elements ( $\mathrm{Li}, \mathrm{Na}, \mathrm{Mg}, \mathrm{K}, \mathrm{Ca}, \mathrm{Mn}, \mathrm{Cu}, \mathrm{Zn}, \mathrm{Rb}$, $\mathrm{Sr}, \mathrm{Mo}, \mathrm{Cs}$, and $\mathrm{Ba}), \delta^{13} \mathrm{C}$, and $\delta^{15} \mathrm{~N}$ selected to create the chemical fingerprint. Differences in the chemical fingerprint of samples between sites and over time were assessed using principal components analysis and canonical analysis of principal coordinates. Differences in the chemical fingerprints of samples between production sites provided a classification success rate (leaveone-out classification) of $98.1 \%$, providing a basis for using the approach to test the authenticity of product manufactured at a site. Within one site, the chemical fingerprint of samples produced at the beginning of the production season differed from those produced in the middle and late season, driven predominantly by lower concentrations of $\mathrm{Na}, \mathrm{Mg}, \mathrm{K}, \mathrm{Mn}$, and $\mathrm{Rb}$, and higher concentrations of $\mathrm{Ba}$ and $\mathrm{Cu}$. This observed temporal variability highlights the importance of obtaining samples from throughout the season to ensure a representative chemical fingerprint is obtained for goat WMP from a single manufacturing site. The reconstitution and spray drying of samples from one manufacturer by the other manufacturer enabled the relative influence of the manufacturing process on the chemical fingerprint to be examined. It was found that such reprocessing altered the chemical fingerprint, although the degree
\end{abstract}

Received March 25, 2015.

Accepted October 5, 2015.

${ }^{1}$ Corresponding author: rmcleod@oritain.com of alteration varied among samples and individual elements. The findings of this study support the use of trace elements and stable isotope ratios to test the authenticity of goat WMP, which can likely be applied to other dairy goat products. This approach could be used test to the factory of origin (and potentially batch of origin) of products in the supply chain, thus providing the ability to audit the supply chain and monitor for fraudulent activity.

Key words: dairy goat, whole milk powder, origin, trace elements, stable isotope ratios

\section{INTRODUCTION}

A series of recent food safety scares and quality issues has raised the level of consumer awareness (Moore et al., 2012) and placed added pressure on food producers and retailers to demonstrate that they take such issues seriously. Provenance is often valued when the food product originates from a source that has high standards of food safety, quality assurance, and quality control (Kelly et al., 2005; Carcea et al., 2009).

Chemical profiling techniques have been used to verify the origin (a geographic origin or processing plant) and authenticity of food products (Rossmann, 2001; Kelly et al., 2005; Förstel, 2007). To be effective, such a profile needs to differ on a geographic scale or among manufacturers and be difficult to replicate. Rapid verification of the authenticity of a suspect sample can be assisted by comparison to a database containing profiles of historical samples from the purported origin (Le Bot et al., 2011). Of these profiling techniques, quantification of trace element concentrations and stable isotope ratios have proven to be the most useful and scientifically robust over a wide range of food products (Luykx and van Ruth, 2008). Several review articles have been published covering the application of these techniques in sectors including dairy, meat, honey, beverages, and plant products (Rossmann, 2001; Kelly et al., 2005; Förstel, 2007; Carcea et al., 2009; Ye, 2012).

Less focus has been concentrated on applying this approach for complex processed or manufactured products (Scampicchio et al., 2012), where the addition 
Table 1. Summary of samples of goat whole milk powder included in this study

\begin{tabular}{|c|c|c|c|}
\hline Country of origin & Year received & Year manufactured & Number of samples \\
\hline The Netherlands & 2011 & 2011 & $14^{1,2}$ \\
\hline New Zealand & 2011 & 2011 & 10 \\
\hline Spain & 2011 & 2011 & 1 \\
\hline The Netherlands & 2012 & 2011 & $3^{1}$ \\
\hline New Zealand & 2012 & 2012 & 13 \\
\hline New Zealand & 2014 & 2012 & 1 \\
\hline New Zealand & 2014 & 2013 & 6 \\
\hline New Zealand & 2014 & 2014 & 6 \\
\hline France & 2014 & 2012 & 1 \\
\hline The Netherlands & 2014 & 2014 & 3 \\
\hline Total & & & 58 \\
\hline Total New Zealand & & & 36 \\
\hline Total the Netherlands & & & $20^{1}$ \\
\hline Total Spain & & & 1 \\
\hline Total France & & & 1 \\
\hline
\end{tabular}

of multiple ingredients and physical contact with the processing facility is likely to contribute trace metals, thus further influencing the chemical fingerprint of a finished product. This leads to the question of whether processed products coming out of different processing plants maintain distinctive fingerprints that could be used as the basis for testing product authenticity.

The current study examined differences in the stable isotope ratios and trace element concentrations - the chemical fingerprint-between goat whole milk powders (WMP) produced by a factory in New Zealand with those produced by a factory in the Netherlands. The hypothesis was that a distinct fingerprint could be determined for product produced by each factory that enables the manufacturer of origin to be investigated. Our objectives were (1) to investigate differences in the trace elemental and light isotope composition of samples of goat WMP among samples from multiple global sources; (2) to investigate temporal changes in the trace elemental and light isotope composition of samples of goat WMP produced by a factory in northern New Zealand; and (3) to examine the relative influence of the manufacturing process on the fingerprint of product.

\section{MATERIALS AND METHODS}

\section{Sample Collection and Preparation}

Samples of WMP processed by the New Zealand factory were collected from approximately the middle of individual manufacturing runs. Samples of WMP were sourced from single manufacturing sites in the Netherlands, Spain, and France. The samples from Spain and France were included to provide a point of reference only, as small sample sizes prevented any further inference being drawn. Samples were packaged in foil-lined sachets before subsampling. A total of 58 samples of WMP were sourced between 2011 and 2014, from New Zealand $(\mathrm{n}=36)$, the Netherlands $(\mathrm{n}=20)$, Spain $(\mathrm{n}$ $=1)$, and France $(n=1$; Table 1$)$. None of the WMP samples originating from the New Zealand factory were reprocessed. New Zealand samples were taken over the course of the milking season, beginning in spring and finishing in autumn. Subsampling was conducted in a manner to avoid trace element contamination.

\section{Elemental Analysis}

Subsamples of $\sim 500 \mathrm{mg}$ of WMP were placed in teflon vessels with $10 \mathrm{~mL}$ of quartz-distilled nitric acid. Ten percent of samples were analyzed in triplicate to assess repeatability. For every 20 samples analyzed, the following quality control samples were included: $1 \times$ blank, $1 \times$ matrix matched control, $1 \times$ duplicate sample, and $1 \times$ certified reference material (Skim Milk Powder BCR-063R from the Institute for Reference Materials and Measurements, Geel, Belgium).

Samples were digested using a microwave-accelerated reaction system (MARS6), which employed closed vessel acid digestions (CEM Corporation, Matthews, NC). The heating program increased temperature to $200^{\circ} \mathrm{C}$ over $25 \mathrm{~min}$ and held this for $15 \mathrm{~min}$; maximum available power was 1,800 Watts. Once the acid digestion was complete, the samples were quantitatively transferred to $50-\mathrm{mL}$ polypropylene tubes and dried for 8 $\mathrm{h}$ at $104^{\circ} \mathrm{C}$. The resulting residues were redissolved by adding $10 \mathrm{~mL}$ of $2 \%$ quartz-distilled nitric acid, placing lids on, and heating to $60^{\circ} \mathrm{C}$ for $60 \mathrm{~min}$. Trace element concentrations were quantified using inductively coupled plasma-mass spectrometry (Agilent 7500cs, Agilent Technologies, Santa Clara, CA). Calibration stability was ensured by using a single robust tune and 
digested samples were presented to the instrument as $2 \% \mathrm{HNO}_{3}$ solutions after $10 \times$ dilution. A cocktail of 6 elements were added as internal standards (Be, Ge, Rh, $\mathrm{In}, \mathrm{Tb}$, and $\mathrm{Bi}$ ). These elements were selected to span the mass range of interest and on the basis of their low natural concentrations in the samples. The monitoring of these internal standards over the entire mass range allowed mass biases to be identified.

\section{Isotope Ratio Determination}

Samples for $\delta^{15} \mathrm{~N}$ and $\delta^{13} \mathrm{C}$ analyses were prepared by weighing triplicate $1.2 \pm 0.12-\mathrm{mg}$ subsamples into tin foil capsules. Nitrogen and carbon isotopes were assayed by combustion of the whole material to $\mathrm{N}_{2}$ and $\mathrm{CO}_{2}$ gas in a Carlo Erba NC2500 elemental analyzer (CE Instruments, Milan, Italy) using helium carrier gas enriched with oxygen. The gases were separated on a packed molecular sieve GC column and sent sequentially to the inlet of a Europa Scientific "20/20 Hydra" (Sercon, Crewe, UK) isotope ratio mass spectrometer in continuous flow mode. Raw isotope ratios were normalized to the international scales using laboratory standard materials, assayed with the unknown samples, which have been calibrated against International Atomic Energy Agency standard reference materials, including USGS-40 and USGS-41 (Qi et al., 2004). The laboratory standard used for nitrogen and carbon analysis was EDTA (Elemental Microanalysis Ltd., Okehampton, UK) with $\delta^{15} \mathrm{n}=-0.73 \%$ and $\delta^{13} \mathrm{C}=-38.52 \%$. The typical precision for analysis of control materials is $\pm 0.10 \%$ for $\delta^{15} \mathrm{~N}$ and $\pm 0.05 \%$ for $\delta^{13} \mathrm{C}$.

\section{Statistical Analysis}

Statistical analyses were conducted using the software Primer+Permanova (v6.1.12, Primer-E Ltd., Plymouth, UK). Permanova is a permutation-based technique, and therefore does not assume data to be normally distributed, which is useful when dealing with large data sets of many variables, as in the current study. Initial investigations were based on multidimensional scaling (MDS) plots to look for patterns in the unconstrained data. To assess whether or not the chemical fingerprint of samples differed among manufacturers, MDS plots were constructed based on the Euclidean distance measure. Variables were checked for collinearity, with bivariable correlations $>95 \%$ triggering the exclusion of one variable to reduce model complexity. Elements where $>80 \%$ of samples were below the analytical limit of detection were excluded from further statistical analysis. Trace element data were log-transformed, and all data were centered on the mean and standardized (i.e., remainder divided by the standard deviation). Due to grouping by manufacturer apparent in the MDS, a constrained ordination approach, canonical analysis of principal coordinates (CAP), was taken to determine differences among manufacturer groupings. Canonical analysis of principal coordinates discriminates among a priori groups, similar to linear discriminant analysis. The procedure included cross validation in a leaveone-out procedure to predict group membership (e.g., manufacturer) and thus obtain overall classification success rates. Samples of WMP were categorized as being either New Zealand, Netherlands, or reprocessed Netherlands product (samples from Spain and France were excluded due to insufficient sample numbers). The number of CAP axes $(m)$ was constrained to 4 , to give a relatively low residual sum of squares and high classification success while also considering the relative amounts of CAP axes and samples.

To assess temporal variation in the chemical variables, samples from the New Zealand manufacturer were defined as being manufactured in either early (July-August), middle (September-January), or late (February-May) season. Samples from multiple years were included in this analysis. One-way Permanova tests were performed across these groups for each variable (trace element data log-transformed, factor season group: fixed). A multivariate approach was then taken to assess possible differences in the overall chemical fingerprint among these groupings, following the routine described previously (MDS and CAP), with $m$ restricted to 3 .

\section{RESULTS}

\section{Differentiation by Manufacturer of Origin}

Samples of WMP produced by the New Zealand manufacturer had a larger range in most measurements than those produced by the Netherlands manufacturer (Figure 1). Samples of WMP from the New Zealand manufacturer were high in $\mathrm{Li}, \mathrm{Rb}, \mathrm{Cs}$, and $\mathrm{Ba}$ relative to those manufactured in the Netherlands. A large range was observed in $\delta^{13} \mathrm{C}$ for WMP samples produced by both of these manufacturers, ranging from -21.33 to $-26.63 \%$. The $\delta^{15} \mathrm{~N}$ ranged from 5.38 to $6.81 \%$, with a larger range measured in samples from New Zealand $($ mean $=6.06 \%, \mathrm{SD}=0.31)$ than those from the Netherlands $($ mean $=6.37 \%, \mathrm{SD}=0.22)$. A subset of 13 elements were included in the multivariate statistical analyses ( $\mathrm{Li}, \mathrm{Na}, \mathrm{Mg}, \mathrm{K}, \mathrm{Ca}, \mathrm{Mn}, \mathrm{Cu}, \mathrm{Zn}, \mathrm{Rb}, \mathrm{Sr}$, $\mathrm{Mo}, \mathrm{Cs}$, and $\mathrm{Ba}$ ). In unconstrained multivariate space (MDS) a clear differentiation of samples from different origins was noted, with samples produced in New Zealand clearly separated from samples produced in Europe (Figure 2a). Relatively high-stress loading (2-dimen- 
sional stress $=0.13$ ) indicates further dimensionality is inherent in the model that is not well represented in the 2-dimentional figure; however, the separation of New Zealand and European samples was also apparent in the 3-dimensional model (data not shown). Samples from the New Zealand manufacturer were more variable in multivariate space than those from the manufacturer in the Netherlands. Sample sizes of 1 for Spain and France prevent any conclusions being drawn, but it was interesting to note that these samples were positioned closer in multivariate space to the samples from the Netherlands than they were to those from New Zealand. The Dutch samples that were reprocessed by the New Zealand manufacturer clustered separately from both the Netherlands and the New Zealand samples.

Samples of WMP were well classified into their manufacturing origin (New Zealand vs. Netherlands vs. reprocessed Netherlands) based on their chemical fingerprints (Figure $2 \mathrm{~b}$ ). Sample groupings were differentiated along the CAP1 axis, driven largely by differences in the concentrations of $\mathrm{Sr}, \mathrm{Ba}, \mathrm{Rb}$, and Cs. Samples of WMP from the Netherlands were further differentiated from the reprocessed Netherlands samples along the CAP2 axis, driven mostly by differences in $\delta^{15} \mathrm{~N}$ and the concentration of Li. The overall classification success rate of the model was $98.1 \%$, indicating clear differences between samples from these groupings that could be used in a diagnostic sense to test the claimed manufacturing origin.

\section{Effect of Factory Processing on Chemical Fingerprint}

To examine the effect of factory processing on the chemical fingerprint in more detail, samples of WMP from the manufacturer in the Netherlands were compared with that of the samples of product that were reconstituted and spray dried by the New Zealand manufacturer. In MDS space, samples of reprocessed WMP clustered separately from the original product (Figure 3). A closer look at the change in fingerprint of 2 batches of WMP (Figure 3, Table 2) indicates the size of the effect of factory processing on the fingerprint may be variable, and some elements were more affected or altered than others during processing. Relatively large increases in the concentrations of $\mathrm{Li}$ (increasing by $1,520-2,780 \%$ ) and Cs (increasing by 127-150\%) were measured, and relatively moderate increases in the concentrations of Mn (10-27\% increase), Mo (13-25\% increase), and $\mathrm{Ba}$ (24-48\% increase) also occurred. In Figure 2a, the reprocessed samples are situated in closer proximity to Netherlands WMP than New Zealand WMP.

\section{Temporal Changes in the Chemical Composition of Samples}

Values of $\delta^{13} \mathrm{C}$ and $\delta^{15} \mathrm{~N}$ in New Zealand-produced goat WMP did not differ significantly over the course of the production season (Figure 4). Significantly lower concentrations of $\mathrm{Na}$ [pseudo-F: 5.35, p(permutational): 0.011], Mg [pseudo-F: 7.19, p(permutational): 0.006], K [pseudo-F: 7.62, p(permutational): 0.002], Mn [pseudo$\mathrm{F}$ : 8.92, p(permutational): 0.003], and $\mathrm{Rb}$ [pseudo-F: $5.60, \mathrm{p}$ (permutational): 0.009] were measured in WMP samples produced at the beginning of the production season compared with the samples produced in the middle and late season. These samples also had significantly higher concentrations of Ba [pseudo-F: 19.10, $\mathrm{p}$ (permutational): 0.001] and $\mathrm{Cu}$ [pseudo-F: 89.14, $\mathrm{p}$ (permutational): 0.001] than samples from the middle and late season. In multivariate space, samples collected in the beginning of the season clustered separately from those taken during the remainder of the season (Figure 5a). No apparent differentiation was noted on the 2-dimensional plot between samples collected in the middle and late season. The relatively high stress loading on the MDS plot (2-dimensional stress $=0.128$ ) indicated that further dimensionality was present; however, samples from the middle and late season were not differentiated in the 3 -dimensional view (not shown). A CAP model (Figure 5b) had a high classification success rate for samples produced during the beginning of the season (differentiated along CAP axis 1; beginning $100 \%$ classification success), but had poorer performance when it came to differentiating samples from the middle and late season (71 and $79 \%$ classification success, respectively). The overall classification success of the model was $79 \%$.

\section{DISCUSSION}

This study has demonstrated that representative samples of goat WMP from manufacturers located in different countries can be differentiated using a combined multi-element and stable isotope ratio approach. Temporal variability in the chemical fingerprint implies that to obtain a representative chemical fingerprint for a manufacturer, samples would need to be analyzed from throughout a production season, and it is also recommended that samples be collected over multiple years to capture any variability in the fingerprint caused by changes in climate and production practice. The hypothesis that a distinct profile can be determined for a product produced by each factory that enables the provenance of product to be tested was supported by the analysis of samples from the 2 manufacturers 

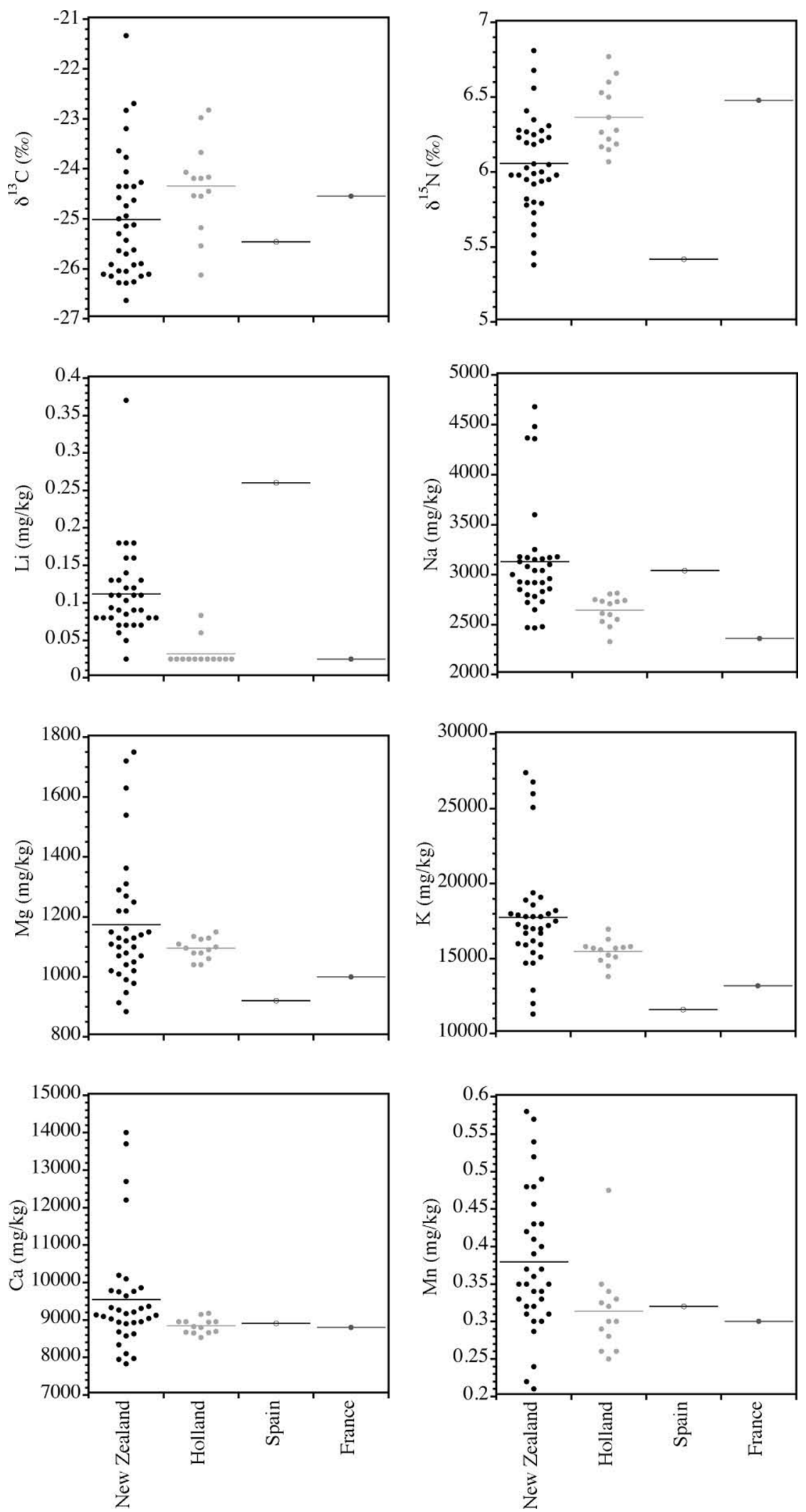

Figure 1. Distribution plots of individual elements or isotope ratios of interest by country of origin. The mean value is represented by a horizontal line for each grouping, and letters (A, B) indicate significant differences between samples from the manufacturers in New Zealand and the Netherlands (permutational $P<0.05$ ). 

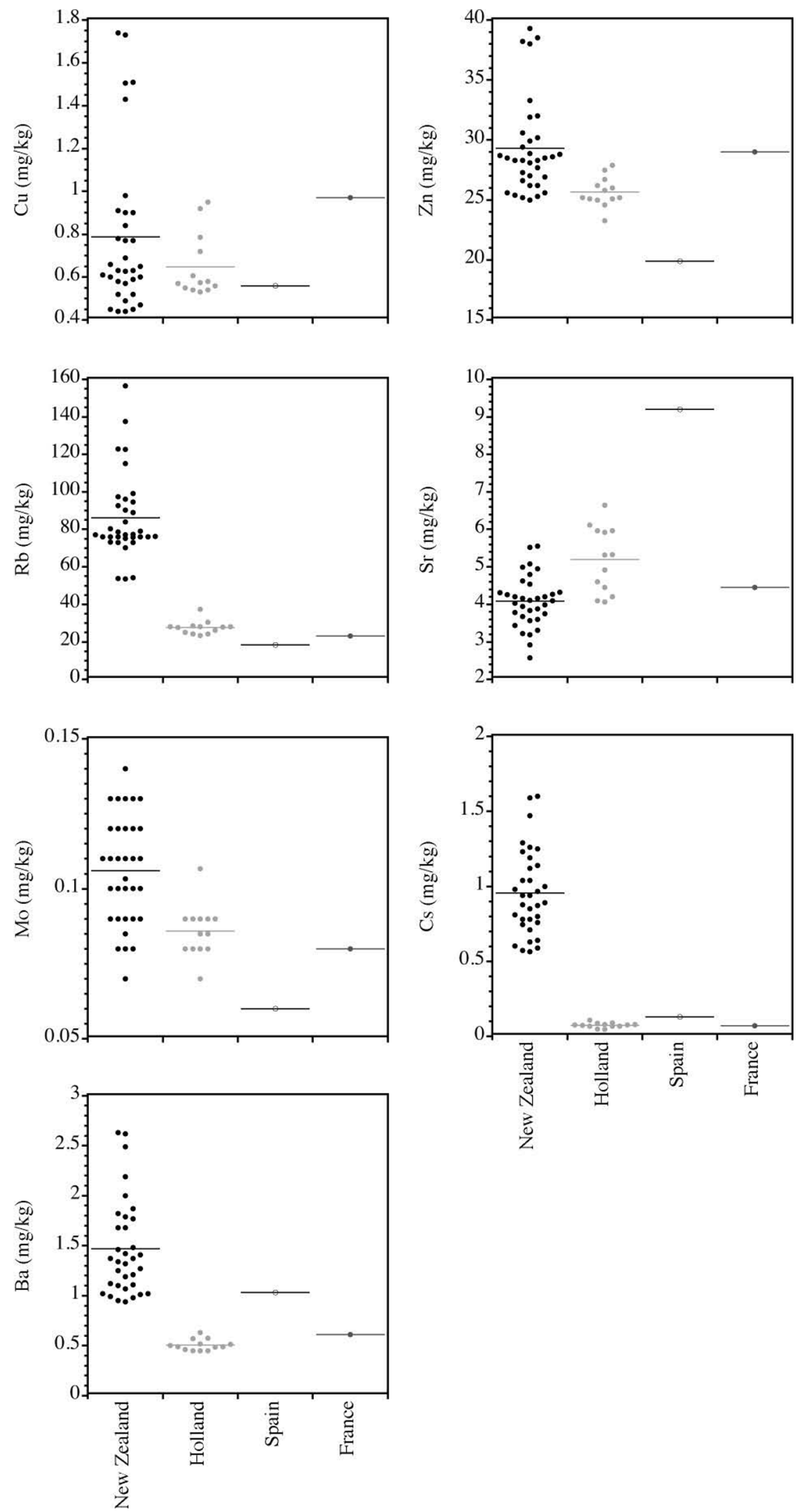

Figure 1 (Continued). Distribution plots of individual elements or isotope ratios of interest by country of origin. The mean value is represented by a horizontal line for each grouping, and letters (A, B) indicate significant differences between samples from the manufacturers in New Zealand and the Netherlands (permutational $P<0.05$ ). 
included in the study. However, analysis of additional manufacturers would be required before the distinctness of the profile can be established.

The sample set from the New Zealand manufacturer was more variable in most measurements than the sample set from the Netherlands. This is likely due a greater number of New Zealand samples, which were possibly more representative of the entire milking season (exact dates of production of samples from the Netherlands were unavailable). Milk composition is influenced by the genetics of the animal, farming practices, stage of lactation, and animal feeds, as well as geographic or environmental influences (Auldist et al., 1998; Crittenden et al., 2007; Santos et al., 2012). Feed provided to dairy herds can vary greatly among farms and global regions. For instance, most dairy animals are fed forages, but also have some supplements, such as maize, soy, canola, wheat, barley, and many others, that can
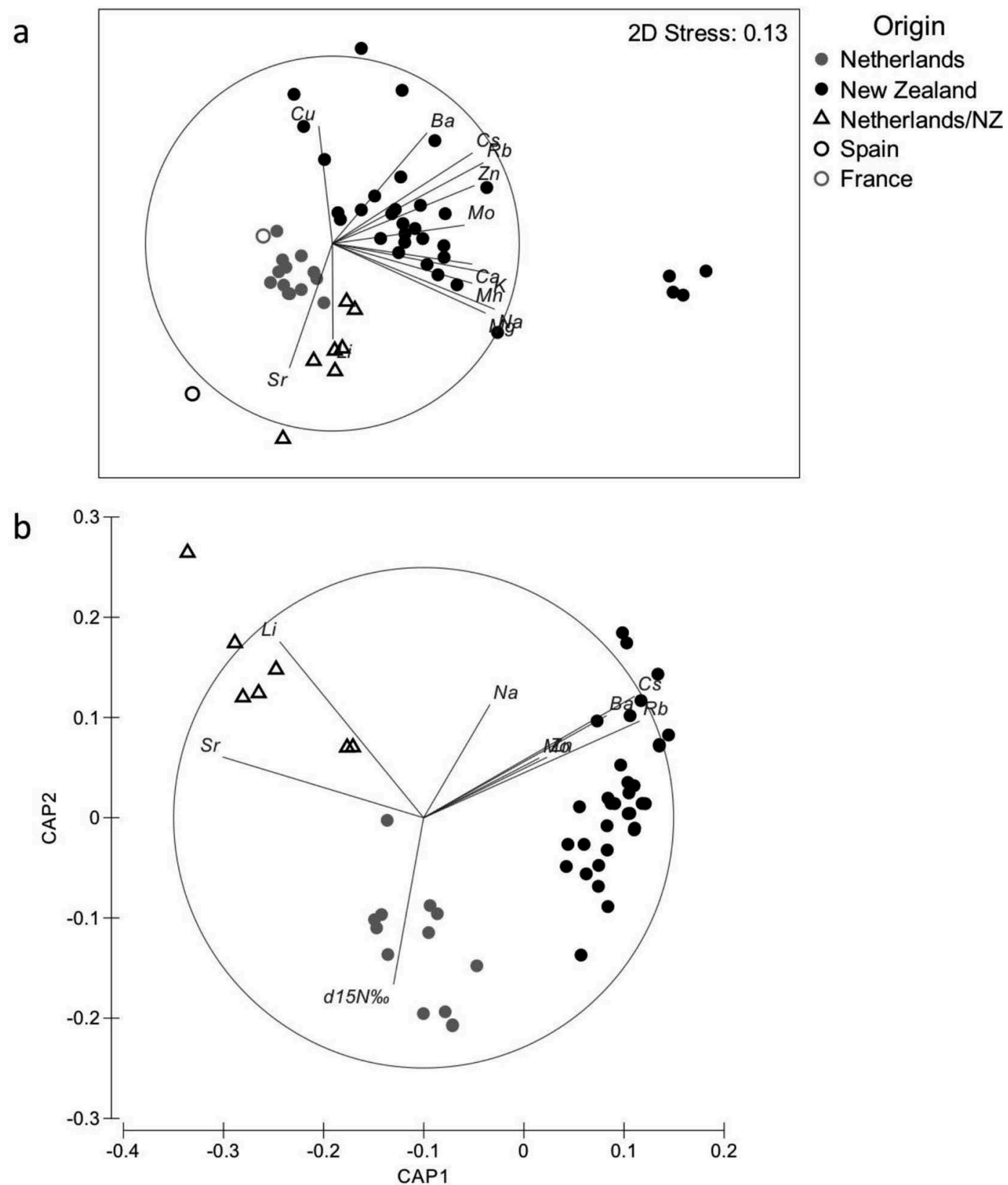

Figure 2. (a) Two-dimensional (2 D) multidimensional scaling plot (unconstrained multivariate space) by origin. (b) First 2 canonical analysis of principal coordinates (CAP) functions, with samples grouped by origin (note reprocessed Dutch samples = Netherlands/NZ), with vectors showing general direction of increase of individual variables within this space. 
Table 2. Change in stable isotope ratios and elemental concentrations during reprocessing

\begin{tabular}{|c|c|c|c|c|}
\hline \multirow[b]{2}{*}{$\begin{array}{l}\text { Variable }(\mathrm{mg} / \mathrm{kg} \text {, unless } \\
\text { otherwise noted) }\end{array}$} & \multicolumn{2}{|c|}{ Batch A } & \multicolumn{2}{|c|}{ Batch B } \\
\hline & Change & $\begin{array}{l}\text { Percent } \\
\text { change }\end{array}$ & Change & $\begin{array}{l}\text { Percent } \\
\text { change }\end{array}$ \\
\hline$\delta^{13} \mathrm{C}(\%)$ & -0.02 & 0 & -0.74 & 3 \\
\hline$\delta^{15} \mathrm{~N}(\%)$ & -0.22 & -3 & -0.16 & -3 \\
\hline $\mathrm{Li}$ & 0.70 & 2,780 & 0.38 & 1,520 \\
\hline $\mathrm{Na}$ & 100.00 & 4 & 370.00 & 14 \\
\hline $\mathrm{Mg}$ & -10.00 & -1 & 85.00 & 8 \\
\hline $\mathrm{K}$ & 0.00 & 0 & $1,000.00$ & 6 \\
\hline $\mathrm{Ca}$ & 75.00 & 1 & 475.00 & 5 \\
\hline $\mathrm{Mn}$ & 0.03 & 10 & 0.07 & 27 \\
\hline $\mathrm{Cu}$ & 0.06 & 10 & 0.06 & 11 \\
\hline $\mathrm{Zn}$ & 0.80 & 3 & 2.30 & 9 \\
\hline $\mathrm{Rb}$ & 0.70 & 3 & 6.75 & 24 \\
\hline $\mathrm{Sr}$ & 0.91 & 15 & 0.09 & 1 \\
\hline Mo & 0.01 & 13 & 0.02 & 25 \\
\hline Cs & 0.10 & 127 & 0.11 & 150 \\
\hline $\mathrm{Ba}$ & 0.11 & 24 & 0.22 & 48 \\
\hline
\end{tabular}

originate from both local and imported sources. Animals are also given trace elements via mineral blocks or oral drenches, which may influence milk composition (Pechova et al., 2008; Nudda et al., 2009).

Goats in New Zealand are farmed similarly to dairy cows, being predominantly pasture fed with kidding concentrated within a few months in July and August (Solis-Ramirez et al., 2011). As a result milk composition is likely to be affected by stage of lactation and

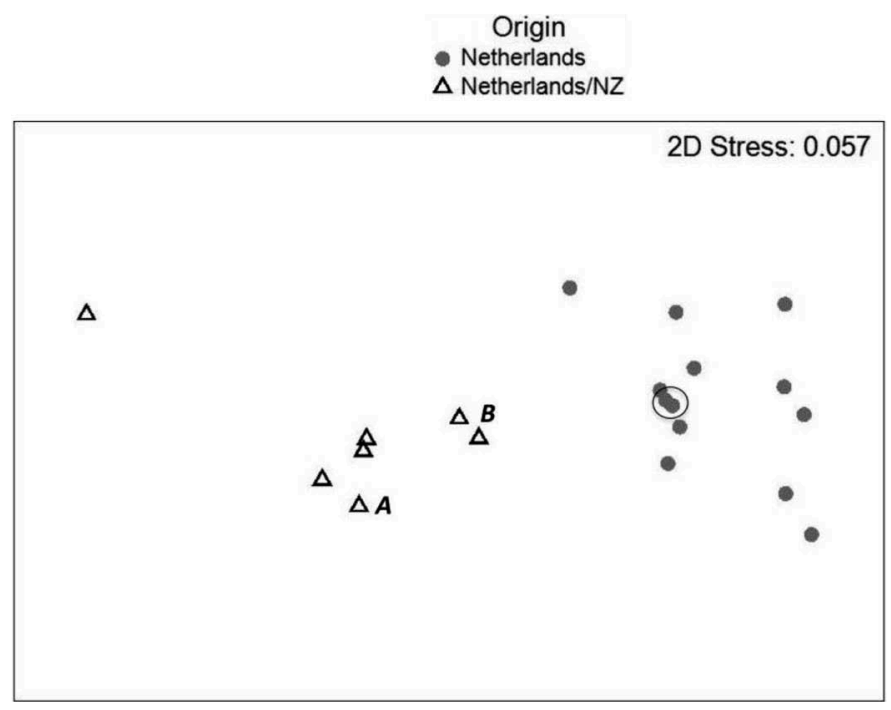

Figure 3. Two-dimensional (2 D) multidimensional scaling plot (unconstrained multivariate space) of samples originating from the Netherlands (gray elipses) and Netherlands samples (open triangles) reconstituted and spray dried at the New Zealand factory. Each point represents a single sample, and distance measure is based on multiple trace elements and stable isotope ratios of $\mathrm{C}$ and $\mathrm{N}$. Two batches are paired with specific before (circled) and after samples (designated by batch A or B) indicated. quality, and type and availability of feed, which varies across a season (Auldist et al., 1998). It is likely that these variables have combined to cause the observed variation in minor milk components in the WMP samples from New Zealand.

Despite the apparent seasonal variability in the chemical fingerprint of goat WMP, clear differentiation was maintained among samples from the 2 manufacturers, which supports using this approach to verify manufacturer of origin for this product. This is in keeping with previous studies that have demonstrated the ability to differentiate milk based on trace element concentrations and stable isotope ratios when applied to an individual country of origin (Crittenden et al., 2007; Santos et al., 2012; Ehtesham et al., 2013). Studies have also investigated chemical fingerprinting of processed dairy products including cheese (Bontempo et al., 2011; Camin et al., 2012; Silva et al., 2014), butter (Rossmann et al., 2000; Bassbasi et al., 2014), and milk powders (Ehtesham et al., 2013). However, these studies tended to focus on a single sampling event, and therefore did not consider temporal variability in the fingerprint. The present study was the first to explore whether products from manufacturers from different countries may be differentiated. It also included the influence of the manufacturing process on the composition of the chemical fingerprint dairy products produced in different countries.

Reprocessing of WMP from the manufacturer in the Netherlands by the New Zealand manufacturer caused a shift in the chemical fingerprint of the WMP samples, to the point where they were clearly differentiated from both the Netherlands and the New Zealand product. Nevertheless, these samples were more similar to the Netherlands fingerprint than the New Zealand finger- 

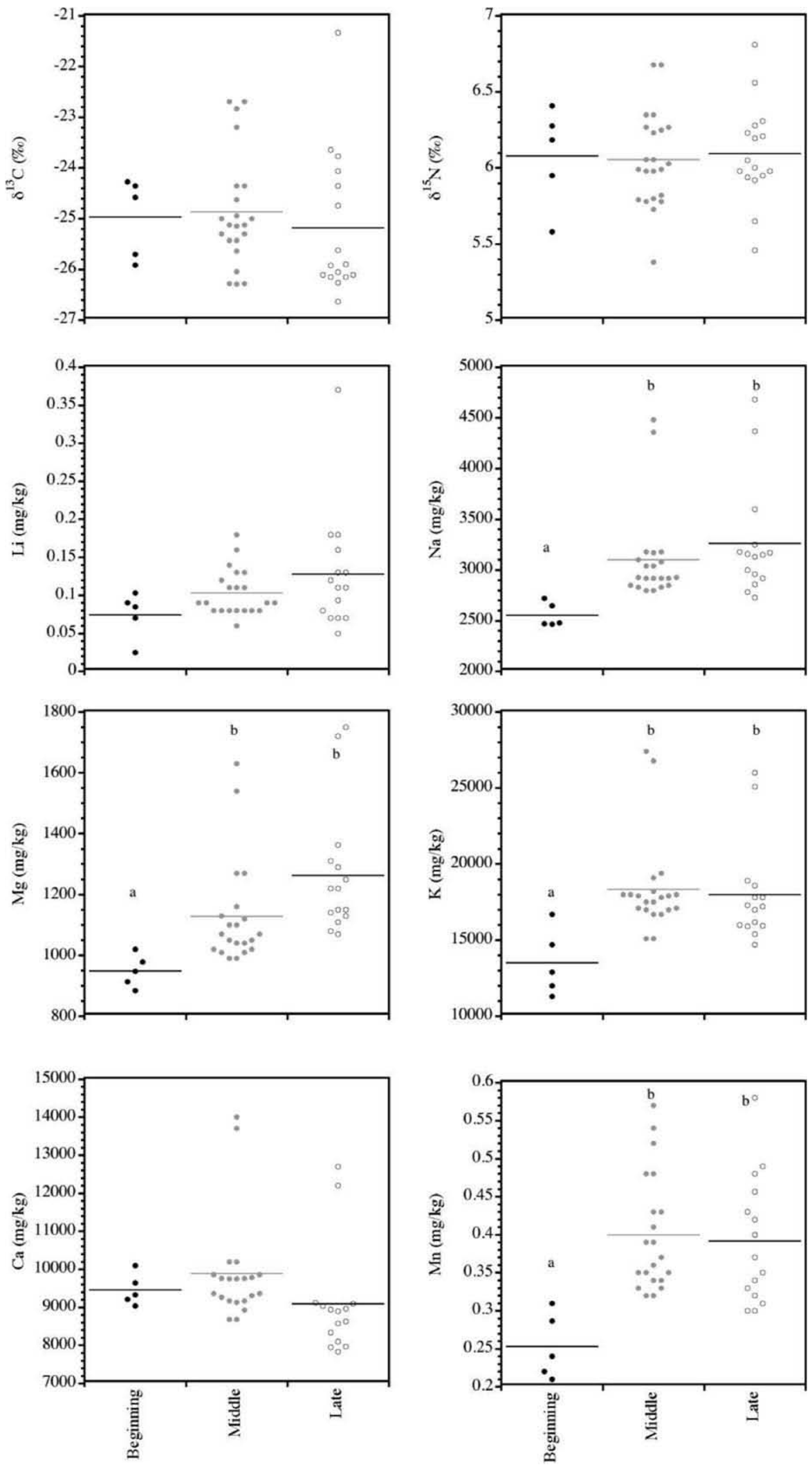

Figure 4. Distribution plots of individual elements or isotope ratios of interest in whole milk powder samples of New Zealand origin, by season. The horizontal lines indicate the mean value for each grouping, and letters indicate significant differences among groupings (permutational $P<0.05)$. 

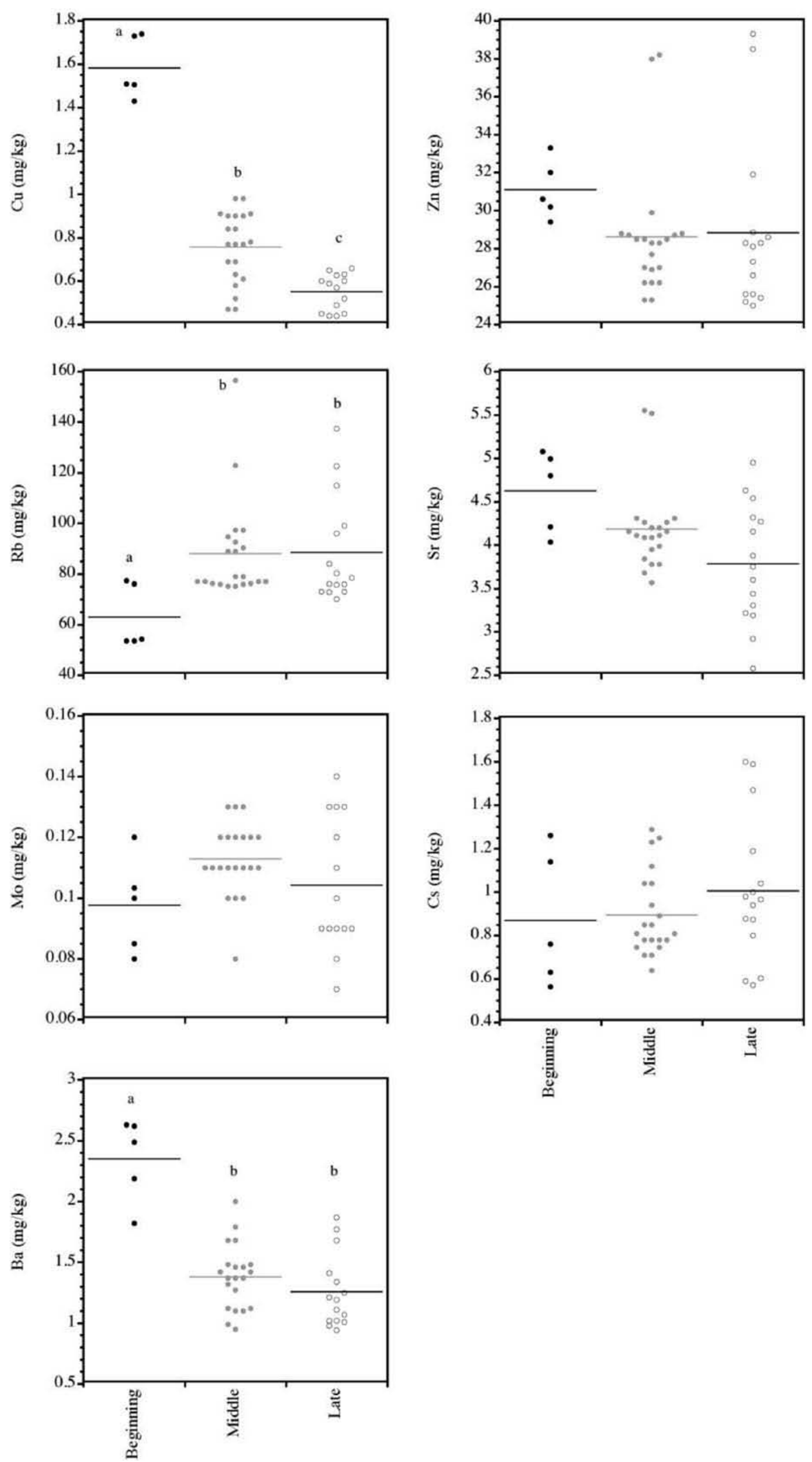

Figure 4 (Continued). Distribution plots of individual elements or isotope ratios of interest in whole milk powder samples of New Zealand origin, by season. The horizontal lines indicate the mean value for each grouping, and letters indicate significant differences among groupings (permutational $P<0.05$ ). 
print, suggesting that the influence of the processing plant on the fingerprint is less than that of the environmental or geographic contribution. The implication of this finding is that, even during reprocessing, the geographic fingerprint is maintained to some respect, which could enable the production history of a product to be verified.

In conclusion, the present study shows that it is possible to apply the chemical fingerprint approach to verify the source of the product by working at the manufacturer or factory, and potentially individual batch, level. Many processed dairy products incorporate ingredients other than fresh milk, and these ingredients may vary in source, which may not be local. This would need to be factored in to any sampling program that is put in place to determine provenance of more complex nutritional formulations, like formula for infants and young children. Similarly, it is likely that the chemical
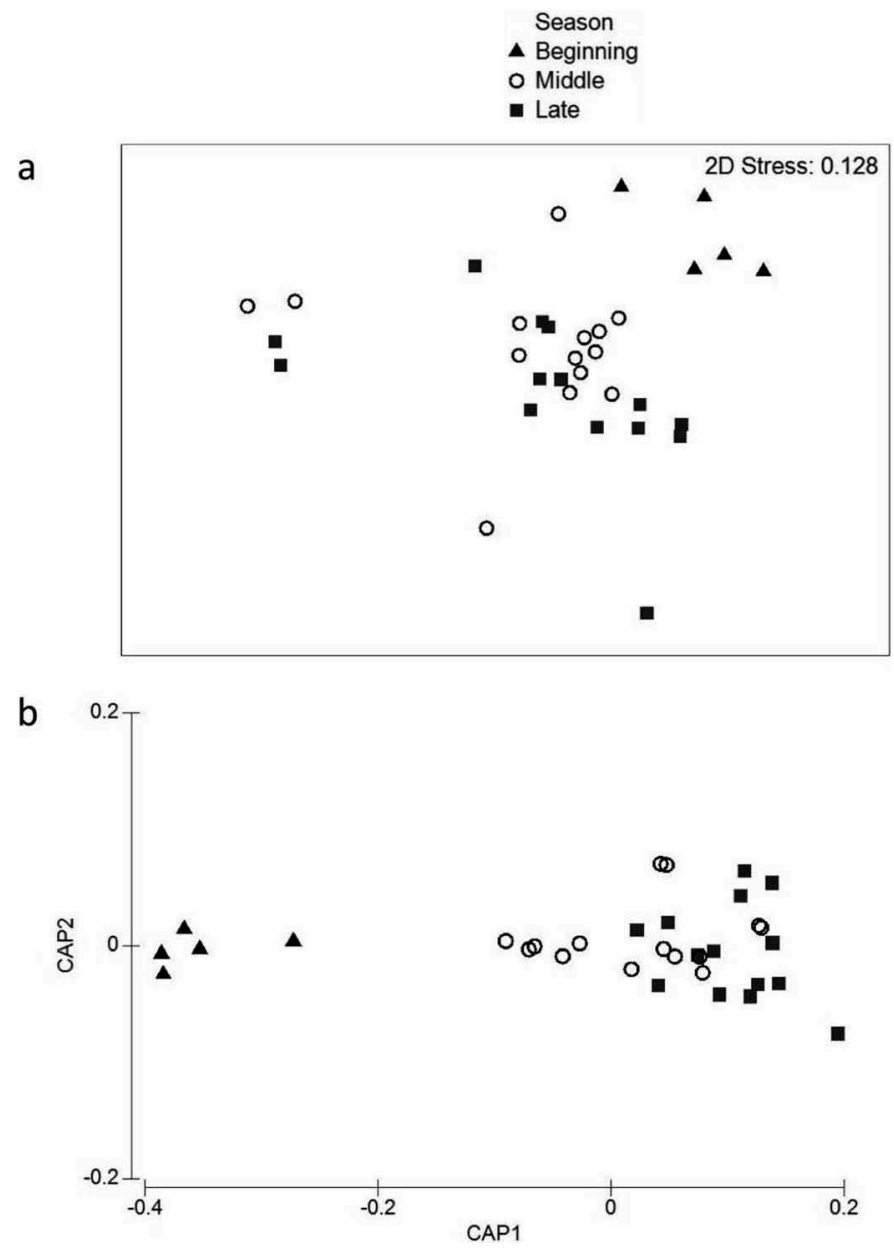

Figure 5. (a) Two-dimensional (2 D) multidimensional scaling plot (unconstrained multivariate space) by country of origin. (b) First 2 canonical analysis of principal coordinates (CAP) functions, with samples grouped by season. fingerprint of WMP, and the extent of variability of the fingerprint for WMP per producer will be vulnerable to change should the specifications (proportion of added ingredients) and sources of specific ingredients change over time. Compliance agencies or whomever use this type of technique would also need to be aware that reprocessing can also influence the chemical profile.

\section{REFERENCES}

Auldist, M. J., B. Walsh, and N. Thomson. 1998. Seasonal and lactational influences on bovine milk composition in New Zealand. J. Dairy Res. 65:401-411.

Bassbasi, M., M. De Luca, G. Ioele, A. Oussama, and G. Ragno. 2014. Prediction of the geographical origin of butters by partial least square discriminant analysis (PLS-DA) applied to infrared spectroscopy (FTIR) data. J. Food Compos. Anal. 33:210-215. http:// dx.doi.org/10.1016/j.jfca.2013.11.010.

Bontempo, L., R. Larcher, F. Camin, S. Hölzl, A. Rossmann, P. Horn, and G. Nicolini. 2011. Elemental and isotopic characterisation of typical Italian alpine cheeses. Int. Dairy J. 21:441-446. http:// dx.doi.org/10.1016/j.idairyj.2011.01.009.

Camin, F., R. Wehrens, D. Bertoldi, L. Bontempo, L. Ziller, M. Perini, G. Nicolini, M. Nocetti, and R. Larcher. 2012. H, C, N and S stable isotopes and mineral profiles to objectively guarantee the authenticity of grated hard cheeses. Anal. Chim. Acta 711:54-59. http://dx.doi.org/10.1016/j.aca.2011.10.047.

Carcea, M., P. Brereton, R. Hsu, S. Kelly, N. Marmiroli, F. Melini, C. Soukoulis, and D. Wenping. 2009. Food authenticity assessment: ensuring compliance with food legislation and traceability requirements. Qual. Assur. Saf. Crop. Foods 1:93-100. http://dx.doi. $\operatorname{org} / 10.1111 / j .1757-837$ X.2009.00011.x.

Crittenden, R. G., A. S. Andrew, M. LeFournour, M. D. Young, H. Middleton, and R. Stockmann. 2007. Determining the geographic origin of milk in Australasia using multi-element stable isotope ratio analysis. Int. Dairy J. 17:421-428. http://dx.doi.org/10.1016/j. idairyj.2006.05.012.

Ehtesham, E., W. T. Baisden, E. D. Keller, A. R. Hayman, R. Van Hale, and R. D. Frew. 2013. Correlation between precipitation and geographical location of the $\delta^{2} \mathrm{H}$ values of the fatty acids in milk and bulk milk powder. Geochim. Cosmochim. Acta 111:105-116. / http://dx.doi.org/10.1016/j.gca.2012.10.026.

Förstel, H. 2007. The natural fingerprint of stable isotopes-Use of IRMS to test food authenticity. Anal. Bioanal. Chem. 388:541544. http://dx.doi.org/10.1007/s00216-007-1241-z.

Kelly, S., K. Heaton, and J. Hoogewerff. 2005. Tracing the geographical origin of food: The application of multi-element and multiisotope analysis. Trends Food Sci. Technol. 16:555-567. http:// dx.doi.org/10.1016/j.tifs.2005.08.008.

Le Bot, B., Y. Oulhote, S. Deguen, and P. Glorennec. 2011. Using and interpreting isotope data for source identification. Trends Anal. Chem. 30:302-312. http://dx.doi.org/10.1016/j.trac.2010.10.015.

Luykx, D. M. A. M., and S. M. van Ruth. 2008. An overview of analytical methods for determining the geographical origin of food products. Food Chem. 107:897-911. http://dx.doi.org/10.1016/j. foodchem.2007.09.038.

Moore, J. C., J. Spink, and M. Lipp. 2012. Development and application of a database of food ingredient fraud and economically motivated adulteration from 1980 to 2010. J. Food Sci. 77:R118-R126. http://dx.doi.org/10.1111/j.1750-3841.2012.02657.x.

Nudda, A., G. Battacone, M. Decandia, M. Acciaro, F. Aghini-Lombardi, M. Frigeri, and G. Pulina. 2009. The effect of dietary iodine supplementation in dairy goats on milk production traits and milk iodine content. J. Dairy Sci. 92:5133-5138. http://dx.doi. org/10.3168/jds.2009-2210.

Pechova, A., L. Misurova, L. Pavlata, and R. Dvorak. 2008. Monitoring of changes in selenium concentration in goat milk during short-term supplementation of various forms of selenium. Biol. 
Trace Elem. Res. 121:180-191. http://dx.doi.org/10.1007/s12011007-8033-3.

Qi, H., T. B. Coplen, H. Geilmann, W. A. Brand, and J. K. Böhlke. 2004 . Two new organic reference materials for $\delta 13 \mathrm{C}$ and $\delta 15 \mathrm{~N}$ measurements and a new value for the $\delta 13 \mathrm{C}$ of NBS 22 oil. Rapid Commun. Mass Spectrom. 17:2483-2487.

Rossmann, A. 2001. Determination of stable isotope ratios in food analysis. Food Rev. Int. 17:347-381. http://dx.doi.org/10.1081/ FRI-100104704.

Rossmann, A., G. Haberhauer, S. Holzl, P. Horn, F. Pichlmayer, and S. Voerkelius. 2000. The potential of multielement stable isotope analysis for regional origin assignment of butter. Eur. Food Res. Technol. 211:32-40. http://dx.doi.org/10.1007/s002170050585.

Santos, L. G. C., E. A. Nadai Fernandes, S. S. N. Silva Cofani dos Santos, M. A. Bacchi, G. A. Sarriés, and F. B. Júnior. 2012. Macro, minor and trace elements in bovine milk from two Brazilian dairy regions. J. Radioanal. Nucl. Chem. 291:207-211. http://dx.doi. org/10.1007/s10967-011-1305-6.
Scampicchio, M., T. Mimmo, C. Capici, C. Huck, N. Innocente, S. Drusch, and S. Cesco. 2012. Identification of milk origin and process-induced changes in milk by stable isotope ratio mass spectrometry. J. Agric. Food Chem. 60:11268-11273. http://dx.doi. org $/ 10.1021 /$ jf302846j.

Silva, A. V., J. F. Hélie, F. de A. Caxito, H. Monardes, A. F. Mustafa, and R. Stevenson. 2014. Multi-stable isotope analysis as a tool for assessing the geographic provenance of dairy products: A case study using buffalo's milk and cheese samples from the Amazon basin, Brazil. Int. Dairy J. 35:107-110. http://dx.doi. org/10.1016/j.idairyj.2013.10.019.

Solis-Ramirez, J., N. Lopez-Villalobos, and H. T. Blair. 2011. Dairy goat production systems in Waikato, New Zealand. Proc. N.Z. Soc. Anim. Prod. 71:86-91.

Ye, N. S. 2012. A minireview of analytical methods for the geographical origin analysis of teas (Camellia sinensis). Crit. Rev. Food Sci. Nutr. 52:775-780. http://dx.doi.org/10.1080/10408398.2010.5085 68. 